\title{
Socio-Ecological Approach to Self-Management of Type 2 Diabetes: Physical Activity and Dietary Intervention
}

\author{
Rashid M. Ansari, John B. Dixon and \\ Colette J. Browning \\ Additional information is available at the end of the chapter \\ http://dx.doi.org/10.5772/56512
}

\section{Introduction}

The incidence of type 2 diabetes is increasing worldwide, resulting in large measure from the increasing prevalence of obesity (Yale, 2000). Diabetes mellitus is a pandemic disease and is one of the main threats to human health (Narayan, 2005). In 2003, 194 million people worldwide, ranging in age from 20 to 79 years, had diabetes. It is projected that this number will be increased by $72 \%$ to 333 million by 2025 , and nearly $80 \%$ of these cases will be in the poorer industrialized countries (IDF, 2003).Type 2 diabetes is also a major public health problem in Pakistan as the middle-aged population in that country is overweight or obese, lack of physical activity, unhealthy food and eating habits exposing this population to a high risk of type 2 diabetes (Ansari, 2009). In the local context, prevalence of Type 2 diabetes in Pakistan for the year 2000 was $7.6 \%$ (5.2 million populations) and for 2030 it will increase to around $15 \%$ (13.8 million populations) and as such Pakistan is ranked $7^{\text {th }}$ on diabetes prevalence list $(\mathrm{WHO}$, 2004). It was found by Jafar et al (2006) that on the age-specific prevalence of overweight and obesity, more than $40 \%$ of women and $30 \%$ of men aged $35-54$ years were classified as overweight or obese.

Despite the high prevalence of diabetes and serious long term complications, there is still lack of established evidence-based guidelines for self-management (ADA, 2006) and translation of practice recommendations to care in Asian countries (Rayappa et al. 1998) and as well as in developed countries (Chin et al. 2000). Therefore, promoting an active lifestyle or regular exercise has become the highest public health priority in that country to overcome the onslaught of type 2 diabetes and in this context this project is very significant as it addresses this important problem of type 2 diabetes. There is a need for self-management approach for patients of type 2 diabetes and the assessment of quality of diabetes care in the community can 
help draw attention to the need for improving diabetes self-management and provide a benchmark for monitoring changes over time.

\section{Brief literature review}

A systematic review of the literature was carried out to cover socio-ecological approach to selfmanagement of type 2 diabetes. Electronic databases were searched, including Cochrane library, Medline, Embase. References of all retrieved articles were checked for relevant studies.

The selection of studies was based on the following criteria:

Interventions: educational interventions compared with usual care, physical activity and diet interventions, behavioural intervention.

Participants: middle-aged population, aged 30-65 with poorly controlled type 2 diabetes.

Outcomes: Studies must report haemoglobin $(\mathrm{HbA} 1 \mathrm{c})$ or hypoglycemia episodes, diabetic complications, cardiovascular disease and quality of life.

Design: The studies related to socio-ecological approach to self-management of type 2 diabetes were included. The search key words were type 2 diabetes, socio-ecological intervention and self-management.

The literature survey revealed that diabetes self-management education is the cornerstone of diabetes care (Mensing et al. 2007). There are several studies indicated an association between diabetes self-management and improved diabetes knowledge and self-management behaviours and improved clinical outcomes (Norris et al. 2001; Philis-Tsimikas et al. 2004). However, authors of a meta-analysis of diabetes self-management programmes reported sharp declines in benefits within one month post intervention (Norris et al. 2001) suggesting that selfmanagement interventions alone do not enable individuals to maintain behaviours changes. The improved outcomes were reported when diabetes self-management was carried out for a longer duration, community-based (CDC, 2001), included follow-up support (Norris et al. 2001), and provided culturally sensitive interventions (Philis-Tsimikas et al 2004; Brown et al. 2005), and addressed psychosocial issues (Mauldon et al. 2006; Norris et al. 2001).

In addition, the social interaction between the patients and doctors is of great significance. The patients of diabetes need to engage with a range of health professionals. Gaining knowledge of the patient's perspective builds on traditional models of physician-patient communication (Pendleton et al. 1984) provides greater clarity to the range of lay understandings that should be explored as a component of effective risk communication.

Fisher et al (2005) suggested that the quality clinical care and self management are compatible and dependent on each other and without sound care, individual's efforts may be misdirected and expert clinical care will fall far short of its potential, through patient failure to use prescribed medications to control his blood sugar or to implement its management plans (Fisher et al. 2005). 
A framework for integrating the resources and supports for self-management with key components of clinical care was also provided by Wagner et al (1996) in their chronic care model. A number of studies have also suggested that patient understanding and beliefs about health and illness may be shaped by historical and local contexts (Macfarlane and Kelleher, 2002), whether respondents are thinking about health or behaviour in general or about their own (Blaxter, 1990; French et al. 2001), and personal experience and observation (Davison et al. 1991). The following figure 1 provides a conceptual framework of self-management of type 2 diabetes using the socio-ecological approach.

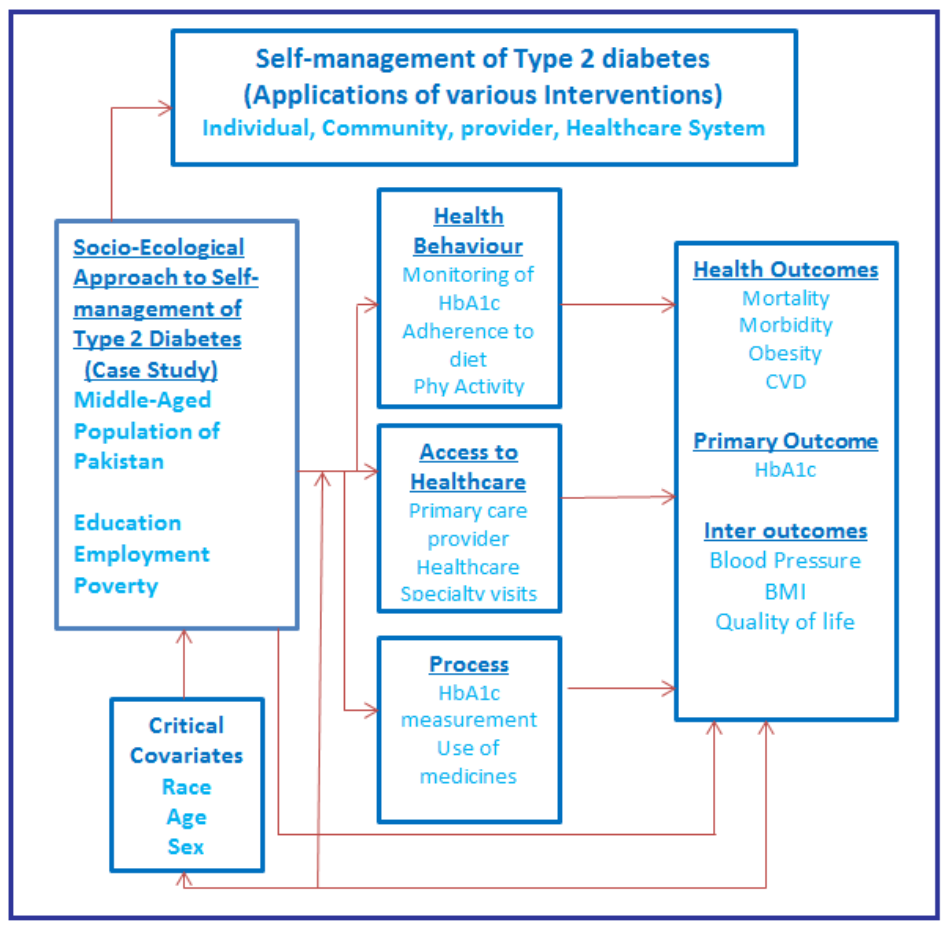

Figure 1. Conceptual framework of self-management of type 2 diabetes

\section{Ecological approach to self-management}

This case study would also demonstrate that the person is solely responsible to take care of his diabetes related problems and its management and therefore the issue of self-management becomes more important for those with chronic disease, where only the patient can be responsible for day to day care over the length of the illness (Lorig and Holman, 2003). It is generally agreed that self-management is required for control of chronic diseases and for 
prevention of disease complications; however, patients generally do not adhere to selfmanagement recommendations (Sherbourne et al. 1992; Gochman, 1997; Glasgow and Eakin, 1998). The adherence to the recommendations and barriers are both problematic for "lifestyle" behaviour such as eating patterns and physical activity rather than medication adherence (Brown, 1990; Roter et al. 1998; Ansari, 2009). This is evident from the culture, tradition and life style behavior of the people of Pakistan that both the eating patterns and physical activity are posing a great deal of difficulties to middle-aged population with diabetes.

There is compelling evidence that higher levels of social support are related to better long-term self management and better health outcomes (Kaplan and Toshima, 1990; Uchino et al. 1996). There is also a significant relationship between support and health where support can be assessed from a variety of sources, including spouses, family, friends and neighbours (Dignam et al. 1986). The relationships between support and immunity (Cohen et al. 1997), health status and health behaviours (Glasgow and Toobert, 1988), mortality and quality of life (House et al. 1988; Glasgow et al. 1997) have also been reported in the literature. King et al (2010) has demonstrated that self-efficacy, problem solving, and social environment support are associated with diabetes self-management behaviours.

\section{Health services in the local community}

The health services in the community in Pakistan are not adequate and diabetes health management programme in the community health clinics does not provide enough help and support to the patients. Shortage of community doctors and expensive consultation with private doctors make the life of patients more difficult in terms of managing their diabetes in that region of Pakistan.

These clinics in Pakistan face special challenges to provide diabetes care to the poor patients as most of these clinics do not meet the evidence-based quality of care standards as compared to the targets established by the American Diabetes Association (ADA, 2000). Similar cases have been reported in several studies in diversified health care settings; including academic institutions (Peters et al. 1996), health maintenance organization (Miller and Hirsch, 1994), health centers (Chin et al. 2000) and medical providers (Chin et al. 1998) where substantial portion of diabetes care does not meet the evidence-based quality of standard care. Marshall et al (2000) have reported that community-based health clinics and their patients have fewer resources than the private clinics and the clinics often lack access to integrated delivery system, and their small size limits the financial feasibility of full-time teams devoted solely to diabetes care.

\section{Interventions to improve health services in the community}

The health services in the community can be improved by making use of on-going follow-up and support for the self-management of diabetes which has shown promising results (Norris 
et al. 2002). For the poor patients in that region of Pakistan where access to the community doctors is not easy and private doctors are not affordable, support may be provided through telephone calls (Weinberger et al. 1995) or the internet (McKay et al. 1998). It has been reported that telephone monitoring of patients, combined with nurse follow-up and tailored information has been shown to reach low income patients and helped them managed their blood sugar level and reduced levels of depression (Piette et al. 1999; Piette et al. 2000).

Another strategy to improve the health services in the community is the group visit to medical clinics by the patients of diabetes (Beck et al. 1997) in which all the patients in a particular category visit the physicians for general check-up including the educational and supportive discussions. Evaluation of this type of strategy has indicated impressive effects on glycosylated hemoglobin and other measures to usual care (Trento et al. 2001).

\section{Self-management approach in local context}

In order to meet the main objective of this study, the socio-ecological approach to selfmanagement of type 2 diabetes will be applied to middle-aged population of Pakistan using case study approach. The case study is most suitable as it integrates the skills and choices of individuals with the services and support they receive from (a) the social environment of family, friends, organizations and cultures (b) the physical and policy environments of neighbourhoods, communities and governments (Stokols, 1996). The self management from an ecological perspective requires access to a variety of resources, including services provided by professionals and support for the initiation and maintenance of healthy behaviours (Glasgow, 1995; Glasgow et al. 2000).

There is only one study conducted in Pakistan on diabetes knowledge, beliefs and practices among people with diabetes (Rafique et al. 2006). The study provided further evidence that there was a lack of information available to people with diabetes in Pakistan as the large population has never received any diabetes education at all (Rafique et al. 2006). Also, the study was conducted in an urban university hospital, where diabetes education may be more readily available as compared to rural areas where people have less access to information and will have even poorer diabetes perception and practices.

This case study would make a unique contribution to public health in the rural area of Pakistan. This will be first type detailed study of diabetes self-management among the population of Pakistan. It will address the issues and the ways in which diabetes in viewed and managed in that region. The study will also be useful for health care professionals suggesting that coping with diagnosis and living with diabetes is affected by a complex constellation of factors, including life circumstances, social support, gender roles and economy. 


\section{Aims and objectives}

The main objective of this study is to examine the role of physical inactivity and obesity in the development of type 2 diabetes and its self-management in a middle-aged population living in rural area of Pakistan and to evaluate a lifestyle intervention (Physical Activity and Diet) in the management of type 2 diabetes. The study would use the qualitative health approach conducting one-on-one interviews with a sample of informants - patients of type 2 diabetes $(n=210)$ and to explore patients perceptions and experiences of undertaking physical activity and eating behaviour as part of their diabetes self-management. In addition, the study would analyze how the health issue related to diabetes is viewed and addressed in the community and identify the barriers to diabetes care in community and healthcare clinics and would use the concepts of socio-ecological approach to self-management of type 2 diabetes.

This research protocol design addresses the lifestyle interventions for lowering hemoglobin $(\mathrm{HbA} 1 \mathrm{c})$ in this randomized controlled trial and determines whether the intervention of physical activity and diet in combination of usual medical care lowers $\mathrm{HbA} 1 \mathrm{c}$ in patients with type 2 diabetes. These types of trials are critical and significant in determining if the culturally tailored interventions are effective in the practical world in which patients live as these patients with diabetes in sub-continent may have different characteristics than those in other western countries due to their eating of different foods and drinking habits.

In addition, this study will help to minimize the gap between the physician-patient understanding and management of diabetes and to identify the barriers to self management of diabetes and quality of life. This study will contribute to improving the quality health care for diabetes in health clinics in that region and would recommend a multifactorial approach emphasizing patient education, improved training in behavioural change for providers, and enhanced delivery system (Chin et al. 2000). The understanding of people about diabetes and susceptibility to diabetes is linked to family, community and society and therefore, this study will impress upon the need to recognize that in developing strategies and interventions to address diabetes, self-care, family support, community education and community ownership are important (Weeramanthri et al. 2003; Wong et al. 2005).

Research Questions: The research questions have been formulated as follows:

1. Will this study help to enhance the patient understanding of self-management of diabetes and will it minimize the gap between the physician-patient interactions?

2. Will hemoglobin $(\mathrm{HbA} 1 \mathrm{c})$ improve after the 90 days trial of lifestyle interventions in patients with poorly controlled type 2 diabetes?

3. Will physical activity and healthy diet lead to reducing the Body Mass Index (BMI) and consequently the risk of diabetes in patients of type 2 diabetes in that region?

Hypotheses: The following hypotheses are to be tested in this study:

1. The lifestyle interventions (physical activity and diet) in patients with poorly controlled diabetes will lead to reduction of $1 \%$ hemoglobin $(\mathrm{HbA} 1 \mathrm{c})$ in 90 days trial. (HbA1c as Primary outcome variable) 
2. The self-management of type 2 diabetes will reduce $5 \%$ weight in patients in 90 days trial and consequently the BMI (BMI as secondary outcome variable)

\section{Justification of hypotheses}

The justification of the first hypothesis stem from the fact that the clinical complications are significantly associated with glycemia (Stratton et al. 2000) and it has been reported that that each $1 \%$ reduction in hemoglobin (HbA1c) is associated with reductions in risk of $21 \%$ for any end point related to diabetes, $21 \%$ for deaths related to diabetes, $14 \%$ for myocardial infarction and 37\% for microvascular complications (DCCT, 1996; UKPDS, 1998). The second hypothesis is related to Body Mass Index (BMI) and weight reduction which are measures of obesity and linked to the development of problems in glycemic control and are major risk factors for the development of cardiovascular disease (Michael, 2007).

\section{Study design and sampling method}

The patients will be recruited from the diabetic medical centre in rural area of Peshawar conducting the study of management of type 2 diabetes among the population aged 30-65 years. The eligibility of patients will be subjected to further screening if their records will not be found in the clinic database. The patients with diabetes having HbA1c $>7.0 \%$ will be included in this study and patients having coexisting liver, kidney or thyroid disorder will be excluded from this study. The Word Health Organization (WHO, 2006) diabetes criteria will be followed in the selection of the patients with diabetes as indicated in Table 1.

\begin{tabular}{ccc}
\hline Condition & 2 hour glucose & Fasting glucose \\
\hline Normal & $\mathrm{mmol} / \mathrm{l}(\mathrm{mg} / \mathrm{dl})$ & $\mathrm{mmol} / \mathrm{l}(\mathrm{mg} / \mathrm{dl})$ \\
\hline Impaired fasting glycaemia & $<7.8(<140)$ & $<6.1(<110)$ \\
\hline Impaired glucose tolerance & $<7.8(<140)$ & $\geq 6.1(\geq 110) \&<7.0(<126)$ \\
\hline Diabetes mellitus & $\geq 7.8(\geq 140)$ & $<7.0(<126)$ \\
\hline
\end{tabular}

Table 1. World Health Organization (WHO, 2006). Diabetes Criteria for patients

All the participants will adhere to their usual medications as recommended by their doctors. In order to assess the effectiveness of this intervention, it was advised not to modify the medications during this trial. In addition, participants will be advised not to take any other new treatments for the management of type 2 diabetes during this study. All participants will be contacted again after 90 days (3-months) to give their blood sample for $\mathrm{HbA1c}$ testing, their weight will be taken and BMI will be calculated. 


\section{Study population and randomization}

Initially 325 patients with type 2 diabetes will be invited to pre-randomized interview, out of which only 210 patients will be included in the actual trial. For the purpose of this trial, it is expected that out of the 325 patients, 93 patients will not meet the inclusion criteria and 22 patients might refuse to participate in the trial. In that case, two hundred and ten (210) patients will agree to participate and will be required to sign informed consent documents at the clinic where they usually visit for their usual medical care for diabetes. Therefore, 105 patients will be randomized to intervention group (Physical Activity and Diet) and 105 to the control group (usual medical care). Figure 2 shows their progress during the randomized controlled trial. This RCT trial will not be double-blinded as the participants receiving the education on lifestyle modifications in the community and healthcare clinics would know that they are on the active intervention.

Once the randomization phase is completed, all patients will be instructed to follow-up the usual medical care for their diabetes for the duration of the 90 days trial. The patients will not be allowed to adjust their usual medications and follow their previous prescriptions recommended by their doctors. In addition, each patient will be asked to go for blood test for $\mathrm{HbA} 1 \mathrm{c}$ on day 1 and then return to give blood sample after 90 days. In addition, participants will be advised not to take any other new treatments for the management of type 2 diabetes during the trial periods.

Those patients randomized to adhere to physical activity and diet (intervention group) will receive education, advice, and behaviour modification skills to help them to maintain a low fat diet, lose weight (goal of 5\% weight loss) and moderate intensity physical activity such as brisk walking for 150 minutes/week. Those patients randomized to usual medical care (control group) will be instructed to take their normal medicines and follow-up with their doctor as per their normal schedule.

All participants will be contacted again after 90 days (3-months) to give their blood sample for $\mathrm{HbA1c}$ testing, their weight will be taken and BMI will be calculated. At that time, a questionnaire will be sent via e-mail to participants in intervention group to assess the progress of the physical activity and diet intervention and to control group to assess the progress of the treatment with normal medical care only.

\section{Measurement}

The factors which will be measured in this study are the physical activity of participants (an intervention), hemoglobin (HbA1c - primary outcome variable), blood pressure and weight (secondary outcome) whereas the body mass index (BMI) is a calculated variable. The linear regression analysis will be performed after three months between $\mathrm{HbA} 1 \mathrm{c}$ and on the blood glucose results to see the reliability of measurement data and to observe any relationship between the two variables. 




Figure 2. Flow chart describing Randomized Controlled Trial of lifestyle Interventions

Physical activity is a key component of lifestyle modification that can help individuals prevent or control type 2 diabetes. It is considered that diet is probably more important in the initial phases of weight loss, incorporating exercise as part of a weight loss regimen helps maintain weight and prevent weight regain (Klein et al. 2004). In this study, the message will be given to participants to do 30 minutes of moderate physical activity daily (approximately 8000 step count) and it may offer greater benefits to these patients in managing their diabetes (Wright and Royson, 1996).

For measurement of physical activity, the method of step count using pedometer will be used as it has been demonstrated to have a superior validity of step counts over a questionnaire approach in predicting health markers such as BMI and waist circumference (Ewald et al. 2008). The participants will be given pedometer for a week for the measurement of physical activities (step counts). These participants will be instructed to wear the pedometer on a waist belt, either side and wear it from the early morning till they go to bed in the night. The participants will record the start and end time for each day wearing the pedometer and in the evening record the step count showing on the display without resetting the counter. The participants will return a 7-day diary with a record of all the events. Table 2 shows the baseline characteristics of participants in intervention and control group. 


\begin{tabular}{|c|c|c|c|}
\hline Characteristics & $\begin{array}{l}\text { Intervention Group } \\
\qquad(\mathrm{n}=105)\end{array}$ & $\begin{array}{l}\text { Control Group } \\
(n=105)\end{array}$ & P-value \\
\hline Age (years) & $\begin{array}{l}\text { Mean }(62.5) \pm \\
\text { SD }(10.5)\end{array}$ & $\begin{array}{l}\text { Mean }(59.5) \pm \\
\text { SD (8.5) }\end{array}$ & 0.78 \\
\hline \multicolumn{4}{|l|}{ Sex } \\
\hline Male & $55 \%(n=58)$ & $58 \%(n=61)$ & \\
\hline Female & $45 \%(n=47)$ & $42 \%(n=44)$ & \\
\hline Body Mass Index (Kg/m2) & $\begin{array}{l}\text { Mean (30.8) } \pm \\
\text { SD (6.5) }\end{array}$ & $\begin{array}{c}\text { Mean (30.6) } \pm \\
\text { SD (6.5) }\end{array}$ & 0.40 \\
\hline $\begin{array}{l}\text { Physical Activity } \\
\text { Adherence to diet }\end{array}$ & $\begin{array}{c}95 \%(8000 \text { steps }) \\
98 \%(n=103) \\
2 \%(n=2)\end{array}$ & - & \\
\hline $\begin{array}{l}\text { Baseline Hemoglobin } \\
(\mathrm{HbA} 1 \mathrm{c}) \%\end{array}$ & $\begin{array}{c}\text { Mean (8.5) } \pm \\
\text { SD (1.6) }\end{array}$ & $\begin{array}{c}\text { Mean }(8.4) \pm \\
\text { SD }(0)\end{array}$ & 0.59 \\
\hline Diabetes Medications & $\begin{array}{l}\text { Mean }(1.75) \pm \\
\text { SD }(0.8)\end{array}$ & $\begin{array}{l}\text { Mean }(1.82) \pm \\
\quad \operatorname{SD}(0.8)\end{array}$ & 0.15 \\
\hline
\end{tabular}

Table 2. Baseline characteristics of intervention and control groups in RCT trial (ref: Medical Record)

\section{Method of analysis}

\subsection{Statistical analysis}

The primary outcome will be analysed by an un-paired sample t-test (mean difference between baseline and final $\mathrm{HbA1c}$ ). The statistical analysis, using STATA will be carried out on an intention to treat basis and that will subject to the availability of data at follow up (after 90 days) as well as at entry level for individual patients. The linear regression analysis will be performed after three months between $\mathrm{HbA} 1 \mathrm{c}$ and on the blood glucose results and it is expected that the $\mathrm{HbA} 1 \mathrm{c}$ and the self-glucose monitoring via a glucometer will demonstrate a significant relationship ( $P<0.0001)$ similar to the findings of Nathan et al. $(2008)$ who reported that the linear regression analysis carried out between the $\mathrm{HbA} 1 \mathrm{c}$ and blood glucose (BG) values provided the tightest correlations $\left(\mathrm{BG}=28.7 \times \mathrm{A} 1 \mathrm{C}-46.7, R^{2}=0.84, P<0.0001\right)$, allowing calculation of an estimated average glucose for $\mathrm{HbA} 1 \mathrm{C}$ values. The linear regression equations did not differ significantly across subgroups based on age, sex, diabetes type, race/ethnicity, or smoking status.

\subsection{Data analysis method}

In this study, the thematic analysis of data will be adopted for analysing the data because the method was developed to meet the needs of investigating the experiences, meanings and the reality of the participants (Braun and Clarke, 2006). The method also allows the study to adopt 
the element from constructionist notions - to investigate the ways in which events, realities, meanings, experiences are the effects of a range of discourses operating within a society. There are five stages to complete this method - it follows the sequence of familiarization, generating initial codes, searching for themes, reviewing themes, defining and naming and preparing the report.

\subsection{Sample size estimation}

The study sample size was determined based on the assumption of the estimation of Standard Deviation (SD). Therefore, the study design was selected to detect an effect size of $0.5 \mathrm{SD}$ lowering of $\mathrm{HbA} 1 \mathrm{c}$. It was assumed that $10 \%$ patients might be lost to follow-up in control group over the period of three months and only $5 \%$ patients will be lost to follow-up in intervention group. This assumption was based on impact of education and advice on lifestyle behavioural modifications to patients and overall popularity of this approach among the diabetic patients in sub-continent to manage their glycemic control.

Taking into consideration all these factors, the following parameters were considered: $\alpha=$ Level of significance test $=0.05$, Power $=0.8, \mathrm{~m}=$ the follow-up period 90 days ( 3 months), Standard Deviation $(\mathrm{SD})=0.5$, the sample size was calculated for each group to detect an effect size of $0.5 \mathrm{SD}$. The sample size $(\mathrm{N})$ for each group was $=105$; therefore, the total, $\mathrm{N}=210$ patients were recruited to participate in both the groups. The figure 2 shows $n=210$ patients randomized to each group and their progress during double-blinded fenugreek randomized controlled trial.

\subsection{Calculation of sample size - An alternate method}

Sample Size $(\mathrm{N})=\frac{\mathrm{P} 1 \times(100-\mathrm{P} 1)+\mathrm{P} 2 \times(100-\mathrm{P} 2)}{(\mathrm{P} 1-\mathrm{P} 2)^{2}} \times(\alpha, \beta)$

Where,

$\mathrm{P} 1=\%$ age success expected in intervention group

$\mathrm{P} 2=\%$ age success on the control group, being different from P1

$\alpha=$ Level of significance test

$\beta=$ type II error

Assuming that $\%$ age success P1 $=95 \%, \mathrm{P} 2=90 \%$,

and the factor $\mathrm{f}(\alpha, \beta)=\mathrm{f}(0.05,0.5)=3.8$ (source: Table of $\mathrm{f}(\alpha, \beta)$ - EPID6430 course notes )

Sample Size $(\mathrm{N})=\frac{95 \times(100-95)+90 \times(100-90)}{(95-90)^{2}} \times(3.8)=209$

\section{Clinical settings in pakistan}

Diabetic Medical Center, Ayub Medical College, Abbottabad - Pakistan 
Patients $=$ patients of type 2 diabetes visiting the medical center

Doctors $=$ doctors working in medical center

\section{Minimizing the bias}

It is possible that the outcome measures associated with physical activity and diet interventions will be subject to bias particularly when treatment will be in progress or just afterwards. The main difference between usual medical care alone for the patients and usual medical care with physical activity and dietary interventions will occur after 3 months period of trial. In order to reduce the bias, the questionnaire will be sent to patients at home or via e-mail to minimize any chance that their answers might be affected by actual or perceived influence by medical practitioners at clinic.

\section{Discussions}

The results of this randomized controlled trial will support the research question that lifestyle interventions (physical activity and diet) with usual medical care for type 2 diabetes is more effective than the usual medical care alone. The higher $\%$ age of lost to follow up throughout this trial (Figure 2) in those patients with usual medical care (10\%) than in those in intervention group (5\%) suggests greater satisfaction with physical activity and dietary education and advice. The difference at 3 months follow up is the mean change in HbA1c levels for the intervention group minus the mean change of $\mathrm{HbA} 1 \mathrm{c}$ for the control group. Therefore, the positive differences reflect more improvement in those patients following physical activity and dietary guidelines than in those patients with medical care only.

\subsection{Testing hypothesis 1 (Primary outcome variable - HbA1c)}

The expected changes in $\mathrm{HbA} 1 \mathrm{c}$ from baseline values in patients with type 2 diabetes after 3 months will be calculated by unpaired sample t-test. At 3 months follow-up, the patients would show significantly greater improvement and lower values of HbA1c by $1 \%$. This would support the hypothesis 1 that the lifestyle interventions (physical activity and diet) in patients with poorly controlled diabetes will lead to reduction of $1 \%$ hemoglobin (HbA1c) in 90 days trial.

These finding are in agreement with the studies by Stratton et al (2000) and the United Kingdom Prospective Diabetes Studies (UKPDS, 1998), suggesting that any reduction in $\mathrm{HbA1c}$ is likely to reduce the risk of complications, with the lowest risk being in those with $\mathrm{HbA1c}$ values in the normal range $(<6.0 \%)$. Therefore, the potential results of this trial which have shown improvement in patients of diabetes by lowering $\mathrm{HbA} 1 \mathrm{c}$ by $1 \%$ might be expected to provide similar reductions in morbidity. 


\subsection{Testing Hypothesis 2 (Secondary outcome variable)}

The hypothesis 2 will be supported if we can provide evidence that the type 2 diabetic patients after the 90 days trial would reduce $5 \%$ weight and consequently the BMI as compared to the these values at baseline. The polynomial regression analysis will be used to generate the reference range models as these models do not make assumptions about linearity of step count with age (Wright and Royson, 1996). It is expected to find a correlation of step count with BMI similar to one of the studies (Ansari, 2009) which provided evidence that relationship between physical activity and BMI was found to be statistically significant in a cross-sectional study of a large sample of population and it was also associated with reduced risk of type 2 diabetes with $(\mathrm{RR}=0.82 ; 95 \% \mathrm{CI}=0.68-1.00 ; \mathrm{P}=0.048)$. The changes in $\mathrm{BMI}$ from the base line values will determine the level of reduction in weight and BMI based on physical activity, diet and exercise.

\section{Ethical consideration}

The scientific validity of the study is a fundamental ethical protection and this study has a scientific merit and clinical value as it aims at using the socio-ecological approach to selfmanagement of type 2 diabetes and will help diabetic patients to control their hemoglobin (HbA1c) and help them to understand the importance of physical activity and healthy diet and to enjoy a healthy lifestyle.

All the patients will be provided clear instruction about the study and informed consent will be obtained and ethical clearance will be taken from a legal authority before conducting this study.

Finally, the main contribution of this trial is to provide health professionals (diabetes care providers) and patients with type 2 diabetes an insight into the ways in which diabetes is viewed and managed in that region of Pakistan which will help them in the self-management and treatment of type 2 diabetes.

\section{Conclusion}

It has been demonstrated in this study that the level of HbA1c (primary outcome) will reduce by $1 \%$ in the patients of poorly controlled type 2 diabetes after the 90 days trial of physical activity and dietary interventions and hence will support the hypothesis and the research question. This study will enhance the relationship between the medical practitioner and the patients of diabetes and will improve the health care system in that region of the country in managing and treating the patients with chronic disease such as diabetes. This study will improve upon the overall functioning of community healthcare clinics to diabetes care in terms of recognizing the symptoms of diabetes to early detection and diagnosis, easy access to community doctors. 


\section{Author details}

Rashid M. Ansari, John B. Dixon and Colette J. Browning

School of Primary Health Care, Faculty of Medicine, Nursing and Health Sciences, Monash University, Notting Hill, Australia

\section{References}

[1] American Diabetes Association ((2000). Clinical practice recommendations 2000. Diabetes Care 23 (Suppl. 1):SS116, 2000., 1.

[2] American Diabetes Association ((2006). Standards of medical care in diabetes. Diabetes Care. 29 (suppl. 1): SS42., 4.

[3] Ansari, R. M. (2009). Effect of physical activity and obesity on type 2 diabetes in middle-aged population. Journal of Environmental and Public Health, , 2009, 4-9.

[4] Beck, A, Scott, J, Williams, P, et al. (1997). A randomized trial of group outpatient visits for chronically older HMO members: the cooperative health care clinic. J Am Geriatr Soc. , 45(5), 543-549.

[5] Blaxter, M. (1990). Health and Lifestyles.London: Tavistock/Routledge.

[6] Brown, S. A. (1990). Studies of educational interventions and outcomes in diabetic adults: A meta-analysis revisited. Patient Education and Counselling, , 16, 189-215.

[7] Brown, S. A, \& Hedges, L. V. (1994). Predicting metabolic control in diabetes: a pilot study using meta-analysis to estimate a linear model. Nurs Res , 43, 362-368.

[8] Brownson, R. C, Housemann, R. A, Brown, D. R, et al. (2000). Promoting physical activity in rural communities: walking trail access, use and effects. Am J Pre Med. , 18, 235-241.

[9] Chandler, M. J, Lalonde, C. E, Sokol, B. W, \& Hallett, D. (2003). Personal persistence, identity development, and suicide: a study of Native and Non- native North American adolescents. Monogr Soc Res Child Dev.68 (2): vii-viii, , 1-130.

[10] Chin, M. H, Auerbach, S. B, Cook, S, Harrison, J. F, et al. (2000). Quality of diabetes care in community health centers. Am J Public Health , 90, 431-434.

[11] Chin, M. H, Zhang, J. X, Merrell, K, et al. (1998). Diabetes in the African-American Medicare population: morbidity, quality of care, and resource utilization. Diabetes Care , 21, 1090-1095.

[12] Cohen, S, Doyle, W. J, \& Skoner, D. P. (1997). Social ties and susceptibility to the common cold. JAMA , 277, 1940-1944. 
[13] Davison, C, Smith, G. D, \& Frankel, S. (1991). Lay epidemiology and the prevention paradox. Sociol Health Illn , 13, 1-19.

[14] Dignam, J. T, Barrera, M, \& West, S. G. (1986). Occupational stress, social support, and burnout among correctional officers. Am. J. COMMUN. Psychol. , 14, 177-193.

[15] Ewing, R, Schmid, T, \& Killingsworth, R. (2003). Relationship between urban sprawl and physical activity, obesity, and morbidity. Am J Health Promot. , 18, 47-57.

[16] Fisher, E. B, Brownson, C. A, Tool, O, et al. (2005). Ecological approaches to self-management: The case of diabetes. American Journal of Public Health. , 95, 1523-1535.

[17] Frank, L. D, Engelke, P. O, \& Schmid, T. L. (2003). Health and Community Design: The Impact of the Built Environment on Physical Activity. Washington, DC: Island Press.

[18] French, D. P, Senior, V, Weinman, J, et al. (2001). Causal attributions for heart disease: a systematic review. Psychol Health , 16, 77-98.

[19] Frumkin, H, Frank, L, \& Jackson, R. (2004). Urban Sprawl and Public Health: Designing, Planning, and Building for Healthy Communities. Washington, DC: Island Press.

[20] Gaede, P, Vedel, P, Larsen, N, Jensen, G. V. H, et al. (2003). Multifactorial intervention and cardiovascular disease in patients with Type 2 diabetes. New England Journal of Medicine, , 348, 383-393.

[21] Glasgow, R. E, Strycker, L. A, Toobert, D, et al. (2000). The Chronic Illness Resources Surveys: A social-ecologic approach to assessing support for disease self-management. Journal of Behavioral Medicine. , 23, 559-583.

[22] Glasgow, R. E, \& Eakin, E. G. (1998). Issues in diabetes self-management. In Shumaker, SA et al. (eds). The Handbook of Health Behaviour Change, Springer, New York, , 435-461.

[23] Glasgow, R. E, Toobert, D. J, \& Gillette, C. D. (2001). Psychosocial barriers to diabetes self-management and quality of life. Diabetes Spectrum, , 14, 33-41.

[24] Glasgow, R. E, Ruggiero, L, Eakin, E. G, et al. (1997). Quality of life and associated characteristics in a large diverse sample of adults with diabetes. Diabetes Care, , 20, 562-567.

[25] Glasgow, R. E, \& Toobert, D. J. (1988). Social environment and regimen adherence among Type II diabetic patients. Diabetes Care, , 11, 377-386.

[26] Glasgow, R. E, Wagner, E, Kaplan, R. M, et al. (1999). If diabetes is a public health problem, why not treat it as one? A population-based approach to chronic illness. Ann. Behav. Med. , 21, 1-13. 
[27] Glasgow, R. E. (1995). A practical model of diabetes management and education. Diabetes Care. 18(1), 117-126.

[28] Glasgow, R. E, Orleans, C. T, Wagner, E. H, et al. (2001). Curry SJ, Solberg LI. Does the Chronic Care Model serve also as a template for improving prevention? Milbank Q. , 79(4), 579-612.

[29] Glasgow, R. E, Toobert, D. J, Barrera, M. J, et al. (2005). The Chronic Illness Resources Survey: cross-validation and sensitivity to intervention. Health Educ Res. , 402-409.

[30] Gochman, D. S. (1997). Handbook of Health Behaviour Research II, Plenum Press, NY.

[31] Haire-joshu, D. (1996). Management of Diabetes Mellitus: Perspectives of care across the lifespan. 2nd ed. St. Louis, Mo: C.V. Mosby Co.

[32] Hampson, S. E, Glasgow, R. E, \& Strycker, L. (2000). Beliefs versus feelings: a comparison of personal models and depression for predicting multiple outcomes in diabetes. Br J Health Psychol. , 5, 27-40.

[33] House, J. S, Landis, K. R, \& Umberson, D. (1988). Social relationships and health. Science , $241,540-545$.

[34] HughnerR.S \& Schultz, KS ((2004). Views of Health in the Lay Sector: A Compilation \& Review of How Individuals Think about Health. , 8, 395-422.

[35] Huston, S. L, Evenson, K. R, Bors, P, et al. (2003). Neighbourhood environment, access to places for activity, and leisure-time physical activity in a diverse North Carolina population. Am J Health Promot., 18, 58-69.

[36] International Diabetes Federation ((2003). Diabetes prevalence, available online from: http://www.idf.org/home/index.cfm

[37] Jafar, T. H, Chaturvedi, N, \& Pappas, G. (2006). Prevalence of overweight and obesity and their association with hypertension and diabetes mellitus in an Indo-Asian population. CMAJ , 175(9), 1071-7.

[38] Johnston, M. E, Gibson, E. S, Terry, C. W, et al. (1984). Effects of labelling on income, work and social function among hypertensive employees. Journal of Chronic Disease, , 37, 417-423.

[39] Kahn, E. B, Ramsey, L. T, Brownson, R. C, et al. (2002). The effectiveness of interventions to increase physical activity: a systematic review. Am J Prev Med. , 22, 73-107.

[40] Kaplan, R. M, Ganiats, T. G, \& Sieber, W. J. (1998). The quality of well being scale: Critical similarities and differences with SF-36. International Journal of Quality of Health Care. , 10, 509-520. 
[41] Kaplan, R. M, \& Toshima, M. T. (1990). The functional effects of social relationships on chronic illness and disability. In Sarason, BS, Sarason, I.G and Pierce, G.R (eds). Social Support: An International View, Wiley, New York, , 427-453.

[42] King, D. K, Glasgow, R. E, Toobert, D. J, et al. (2010). Self-efficacy, problem solving, and social environment support are associated with diabetes self-management behaviours. Diabetes Care , 33, 751-753.

[43] Kirmayer, L. J, Gregory, M, \& Tait, L. (2000). The mental health of Aboriginal peoples: transformations of identity and community. Can J Psychiatry. , 45(7), 607-16.

[44] Lorig, K. R, \& Holman, H. (2003). Self-management education: history, definition, outcomes, and mechanisms. Ann Behav Med. , 26, 1-7.

[45] Macfarlane, A, \& Kelleher, D. (2002). Concepts of illness causation and attitudes to health care among older people in the Republic of Ireland. Soc Sci Med , 54, 1389-400.

[46] Marzilli, G. (1999). The Effects of Social Support on Eating Behaviour in Patients with Diabetes." Available: (http://insulin-pumpers.org/textlib/psyc353.pdf).Retrieved May 25, 2009.

[47] May, P. A, Serna, P, Hurt, L, \& Debruyn, L. M. (2005). Outcome evaluation of a public health approach to suicide prevention in an American Indian tribal nation. Am J Public Health., 95(7), 1238-44.

[48] Mckay, H. G, Feil, E. G, Glasgow, R. E, et al. (1998). Feasibility and use of an internet support service for diabetes self-management. Diabetes Educ. , 24, 174-179.

[49] Miller, K. L, \& Hirsch, I. B. (1994). Physicians' practices in screening for the development of diabetic nephropathy and the use of glycosy-lated hemoglobin levels. Diabetes Care , 17, 1495-1497.

[50] Narayan, K. M. V. (2005). The Diabetes Pandemic: Looking for the silver lining: Clinical diabetes. , 23, 51-52.

[51] National Health Survey of Pakistan ((1998). Health Profile of the people of Pakistan, Islamabad, Pakistan: Pakistan Medical Research Council., 1990-94.

[52] Norris, S. L, Lau, J, Smith, S. J, et al. (2002). Self-management education for adults with type 2 diabetes: a meta-analysis of the effect on glycemic control. Diabetes Care. , 25, 1159-1171.

[53] Pendleton, D, Schofield, T, \& Tate, P. (1984). The Consultation: An Approach to Learning and Teaching. Oxford: Oxford University Press.

[54] Peters, A. L, Legorreta, A. P, Ossorio, R. C, et al. (1996). Quality of outpatient care provided to diabetic patients: a health maintenance organization experience. Diabetes Care, 19, 601-606.

[55] Piette, J. D, Weinberger, M, Kraemer, F. B, et al. (2001). Impact of automated calls with nurse follow-up on diabetes treatment outcomes in a Department of Veterans 
Affairs Health care system: a randomized controlled trial. Diabetes Care. , 24, 202-208.

[56] Piette, J. D, Mcphee, S. J, Weinberger, M, et al. (1999). Use of automated telephone disease management calls in an ethnically diverse sample of low-income patients with diabetes. Diabetes Care. , 22, 1302-1309.

[57] Rayappa, P. H. Raju, KNM, Kapur, A et al ((1998). The impact of socio-economic factors on diabetes care. Int J Diab Dev Countries. , 19, 7-15.

[58] Rood, R. P. (1996). Patients and physician responsibility in the treatment of chronic illness: the case of diabetes. American Behavioral Scientist, , 39(6), 729-751.

[59] Roter, D. L, Hall, J. A, Mersica, R, et al. (1998). Effectiveness of interventions to improve patient compliance. Med. Care , 36, 1138-1161.

[60] Sherbourne, C. D, Hays, R. D, \& Ordway, L. (1992). Antecedents of adherence to medical recommendations: Results from the medical outcomes study. J. Behav. Med. , 15, 447-468.

[61] Stokols, D. (1996). Translating social ecological theory into guidelines for community health promotion. Am J Health Promot. 10(4), 282-298.

[62] Thompson, S. J, \& Gifford, S. M. (2000). Trying to keep a balance: the meaning of health and diabetes in an urban Aboriginal community. Social Science and Medicine, , 51, 1457-1473.

[63] Thompson, O. M, Ballew, C, Resnicow, K, et al. (2004). Food purchased away from home as a predictor of change in BMI z-score among girls. Int J Obes Relat Metab Disord., 28(2), 282-289.

[64] Trento, M, Passera, P, Tomalino, M, et al. (2001). Group visits improve metabolic control in type 2 diabetes: a 2-year follow-up. Diabetes Care. , 24, 995-1000.

[65] Uchino, B. N, Cacioppo, J. T, \& Kiecolt-glaser, J. K. (1996). Relationship between social support and physiological processes: A review with emphasis on underlying mechanisms and implications for health. Psychol. Bull. , 119, 488-531.

[66] Wagner, E. H. (1998). Chronic disease management: What will it take to improve care for chronic illness? Effective Clinical Practice. , 1, 1-4.

[67] Wagner, E. H, Austin, B. T, \& Von Korff, M. (1996). Organizing care for patients with chronic illness. Milbank Q. , 74, 511-544.

[68] Wagner, E. H, Glasgow, R. E, Davis, C, et al. (2001). Quality improvement in chronic illness care: a collaborative approach. Jt Comm J Qual Improv. 2001; , 27, 63-80.

[69] Weeramanthri, T, Hendy, S, Connors, C, Ashbridge, D, et al. (2003). The Northern Territory Preventable Chronic Disease Strategy- promoting an integrated and life 
course approach to chronic disease in Australia. Australian Health Review , 26(3), 31-42.

[70] Wareham, N. J, Byrne, C. D, Williams, R, et al. (1999). Fasting proinsulin concentrations predict the development of type 2 diabetes. Diabetes Care, , 22, 262-270.

[71] Weinberger, M, Kirkman, M. A, Samsa, G. P, et al. (1995). A nurse-coordinated intervention for primary care patients with non-insulin-dependent diabetes mellitus: impact on glycemic control and health-related quality of life. J Gen Intern Med. , 10, 59-66.

[72] WHO Expert Consultation ((2004). Appropriate body-mass index for Asian populations and its implications for policy and intervention. Lancet. , 363, 157-63.

[73] Williams, R, Herman, W, Kinmonth, A. L, et al. (2002). Evidence Base for Diabetes Care. Wiley, Chichester.

[74] Wong, M, Haswell-elkins, M, Tamwoy, E, et al. (2005). Perspectives on clinic attendance, medication and foot-care among people with diabetes in the Torres Strait Islands and Northern Peninsula Area. Australian Journal of Rural Health , 13(5), 172-177. 
